\title{
APROXIMACIÓN AL ILÍCITO PUBLICITARIO DENIGRATORIO
}

\section{Estela Bernad: Universidad Jaume I (España)}

\section{Concepto de publicidad denigratoria}

La denigración es un presupuesto de ilicitud publicitaria, tradicionalmente tipificado por nuestro ordenamiento jurídico. Tanto en el viejo EPI, como en el EP ${ }^{1}$, se recogía la prohibición de la denigración por medio de la publicidad, pero es en la actualidad a través de la LGP y de la LCD, donde se reúne de manera completa la prohibición de este ilícito tanto en la parcela personal del competidor, refiriéndose a extremos que afecten a su vida intima y privada, como en la esfera profesional, es decir, aquella denigración que afecta a circunstancias de un competidor o de su actividad empresarial que pueda suponer un menoscabo en el ámbito económicoempresarial.

En la actualidad la LGP, recoge en su art. 6 a) la publicidad denigratoria, como un supuesto de publicidad desleal e indica:

"Es publicidad desleal: a) La que por su contenido, forma de presentación o difusión provoca el descrédito, denigración o menosprecio directo o indirecto de una persona, empresa o sus productos, servicios o actividades 0 circunstancias $o$ de sus marcas, nombres comerciales $u$ otros signos distintivos".

Pero este artículo debemos interpretarlo con el concurso del art. 9 de la LCD, para tener un concepto actual, incardinado dentro del modelo social, del ilícito publicitario denigratorio:

Se considera desleal la realización o difusión de manifestaciones sobre la actividad, las prestaciones, el establecimiento o las relaciones mercantiles de un tercero que sean aptas para menoscabar su crédito en el mercado, a no ser que sean exactas, verdaderas y pertinentes.

$1 \quad$ El art. 10.2 del EP dispone: "Se considera desleal la actividad publicitaria dirigida a provocar confusión entre bienes o servicios, la que tienda a producir el descrédito de los competidores o de los productos de los mismos y, genéricamente, la que sea contraria a las normas de corrección y buenos usos mercantiles". 
En particular no se estiman pertinentes las manifestaciones que tengan por objeto, la nacionalidad, las creencias o ideología, la vida privada 0 cualesquiera otras circunstancias estrictamente personales del afectado.

Como estudiaremos más adelante, de estos dos preceptos se extrae la definición de publicidad denigratoria, al aplicar la determinante fuerza interpretativa que tienen los principios y normas de la LCD sobre la LGP $^{2}$ en aquellos casos donde hubiera conflicto, como es en la aplicación de la "exceptio veritatis" a la denigración publicitaria.

\section{El marco general de la denigración}

El anunciante utiliza la publicidad para dar a conocer sus productos y servicios a los consumidores, y con este fin, les suministra información de las características y cualidades más ventajosas de los mismos.

Pero en algunas ocasiones el anunciante no se limitará a mencionar sus productos 0 servicios, sino que se referirá también, o incluso exclusivamente, a los productos 0 servicios de un competidor ${ }^{3}$, o a su conducta o características personales. Es en este caso donde surge la posibilidad de que se produzca denigración, dado que denigrar es hablar mal de una persona o cosa, destruyendo así su buena fama $u$ opinión ${ }^{4}$. Para protegernos frente a este posible descrédito, nuestro Derecho recoge medios de control frente a ellos tanto con carácter general, en cuanto se produzcan injerencias en la reputación de las personas en el ámbito ilimitado de su privacidad de manera general, como con carácter particular, mientras dichas injerencias se produzcan en cuanto a su actividad específicamente mercantil ${ }^{5}$.

\section{1. Ámbito general}

En el ámbito genérico la denigración se protege mediante los derechos constitucionales que tutelan la garantía de la dignidad de la persona (art. $10 \mathrm{CE}$ ) y la protección del derecho al honor y la propia imagen (art. 18.1 CE), donde se incluye

2 MASSAGUER FUENTES, José, Comentario a la $L C D$, pág. 66.

3 Vid. FERNÁNDEZ-NOVOA, Carlos, «La Publicidad de tono estrictamente personal», Estudios de Derecho de la Publicidad, pág 93.

$4 \quad$ Vid. Diccionario Enciclopedico Larousse. Tomo 8, pág. 2.591

5 Vid. TAPIA HERMIDA, Alberto Javier, « Publicidad comparativa denigratoria y exceptio veritatis (A propósito de la sentencia de la Audiencia Provincial de Barcelona de 3 de Septiembre de 1996)», Revista general de Derecho, 632, 1997, pág. 6436. 
tanto el honor personal, como el profesional ${ }^{6}$ y recogiéndose tanto la protección a las personas físicas como a las jurídicas. Por otro lado, en la legislación ordinaria, se tutela mediante el Código Penal, a través de los delitos contra el Honor (art. 205 y siguientes), así como las normas comunes que regulan la Protección Civil del Derecho al Honor, a la Intimidad Personal y Familiar y a la Propia Imagen (Ley Orgánica 1/1982, de Protección Civil del Derecho al Honor, a la Intimidad Personal y Familiar, y a la Propia Imagen) ${ }^{7}$.

Estos derechos de carácter general protegerán a las personas físicas o jurídicas ${ }^{8}$ en el ámbito de su vida privada, teniendo en cuenta los conflictos que se producen entre los derechos y las libertades, en este caso la libertad de expresión (20.1.a), es decir el derecho a expresar y difundir libremente los pensamientos y la libertad de información (20.1.d) es decir, el derecho a comunicar y recibir libremente información veraz, ambos consagrados en nuestra Constitución.

El honor y la dignidad de la persona son conceptos que suelen ir ligados ${ }^{9}$, entendiendo que el contenido del derecho al honor es hábil y fluido, cambiante y en definitiva "dependiente de las normas, valores, e ideas sociales vigentes en cada momento" 10 . Podríamos entender que consiste en el derecho a la propia estimación, al buen nombre o a la reputación. ${ }^{11}$ Al tipificar la deslealtad del acto denigratorio, tanto en la LGP (art. 6 a) ) como en la LCD (art. 9) se persigue proteger la competencia económica más que la reputación propiamente dicha del competidor,

6 Sentencia de la Sala Primera del Tribunal Supremo de 24 de Julio de 1997, (La Ley 25-111997) establece que "el prestigio profesional de una persona ha de estimarse protegido en el núcleo protegible y protegido constitucionalmente del derecho al honor".

7 Vid. MADRENAS i BOADAS, C., Sobre la interpretación.... Según la autora la LO 1/1982 se aplicaría en aquellos casos en el que los juicios de valor despectivos queden fuera del derecho de la competencia, porque su fín directo o mediato no será promover la contratación.

8 Vid. BIENDICHO GRACIA, Luis F, «La protección del prestigio comercial de la entidad mercantil frente a los actos difamatorios: Los límites del derecho de crítica del consumidor», pág. 1606, "Hasta fecha reciente ha sido polémica, la cuestión relativa a la titularidad del derecho al honor por parte de las personas jurídicas.... en fechas recientes, se ha abierto en la jurisprudencia de nuestros Tribunales una línea jurisprudencial... no puede excluir del ámbito de protección del derecho al honor a las personas jurídicas". Sent T.S.. 9 de Octubre de 1997. Sent del T.S.. De 21 de mayo de 1997. Sentencia del T.S. de 20 de marzo de 1997.

9 Vid. CUCHI DENIA, Javier Manuel, «La libertad de información versus el derecho al honor ¿De la técnica de la ponderación a la prevalencia de la primera?», R.G.D., № 618, 1996, pág. 3490. 
su empresa o sus productos y servicios, y ello es así para preservar el correcto orden del mercado, su transparencia y la libertad de elección y decisión de sus participes $^{12}$.

Pero la empresa o el empresario como partícipes en el mercado tienen una reputación y un prestigio mercantil que deben mantener en el tráfico de su actividad económica $^{13}$, y que en el caso de ser lesionada, justa o injustamente, redundará perjudicialmente en sus intereses y en el correcto desarrollo de su actividad.

La libertad de expresión consiste en la libre expresión de las ideas, pensamientos, opiniones, creencias y juicios de valor. La libertad de comunicación estriba en poder comunicar y recibir libremente información sobre hechos que puedan considerarse noticiables $^{14}$. La libertad de información sería una subespecie de la libertad de expresión, que estaría ligada al principio de veracidad, mientras la segunda únicamente estaría limitada a la ausencia de expresiones injuriosas y que sean innecesarias para las ideas que se transmitan.

La competencia económica tiene como presupuesto la transparencia en el mercado y este a su vez el flujo de la información, lo que implica un papel relevante de la publicidad, al poder mostrar datos e información de interés público.

Por otra parte, el derecho al honor y a la propia imagen y consecuentemente a la dignidad de la persona, puede colisionar a menudo con las libertades enunciadas, produciéndose conflictos entre derechos fundamentales que se resolverán atendiendo a criterios de ponderación ${ }^{15}$. Aunque hoy en día las libertades del art. 20

12 MASSAgUer FUENTES, José, Comentario a la Ley de Competencia Desleal, 1999, pág. 294. "...La protección de la reputación se explica por cuanto tiene de necesario para asegurar un mercado altamente competitivo y transparente, y en particular para asegurar la racional formación de las preferencias y toma de decisiones del mercado por parte de los consumidores, así como el éxito basado en la eficiencia de sus propias prestaciones por parte de los agentes económicos que concurren en el mercado".

13 Vid BIENDICHO GRACIA, Luis, "La protección del prestigio comercial de la entidad mercantil frente a los actos difamatorios: los límites del derecho de crítica del consumidor», La Ley, 1999, pág. 1604. "La Jurisprudencia del T.S., en sentencia de 25 de junio de 1945, ya definió el honor mercantil como..."el conjunto de cualidades que se resumen en la fórmula de verdad sabida y buena fe guardada que deben ser características del comercio...".

14 Vid. STC $107 / 88$ de 8 de junio.

15 Vid. STC 104/86 de 17 de julio "El derecho al honor no es sólo un límite a las libertades del art. 20.1 a) y d) sino que según el art. 18.1 de la Constitución es en sí mismo un derecho fundamental, y por consiguiente cuando del ejercicio de la libertad de opinión 20.1 a) y/o de la libertad de comunicar información por cualquier medio de difusión, 20.1 d) resulte afectado el derecho al honor de alguien, nos encontramos ante un conflicto de derechos, ambos de rango 
CE y en concreto la libertad de información tienen prevalencia (doctrina de la "preferred position") sobre el derecho al honor, no se trata de un derecho absoluto sino que estará limitado por el principio de veracidad y a que se trate de asuntos de interés general o relevancia pública. Como indica MASSAGUER ${ }^{16}$ :

La necesidad de evitar la restricción de la información y de la libre expresión de las ideas en la resolución de las colisiones entre estos derechos y... los intereses contra la competencia desleal....La apreciación del carácter denigratorio de un acto en particular debe, en todos los casos, ser especialmente escrupulosa en la observancia de las exigencias constitucionales relativas a la libertad de expresión y a la libertad de información, de modo que la prohibición de denigración que comporte una restricción de la actividad publicitaria, por cuanto tiene de límite al derecho a la información ha de interpretarse y aplicarse siempre restrictivamente.

Por otra parte, la acción penal, para la protección de la reputación de las personas, a través de los delitos de injurias y calumnias (art. 205 al 216 del CP), solo desplazará a la acción de competencia desleal o de publicidad ilícita, si la conducta ofensiva constituye delito perseguible de oficio, quedando a la elección del afectado la opción de escoger entre la acción penal o la acción de competencia desleal o de publicidad ilícita en el caso de constituir un delito perseguible a instancia de parte.

Por lo que respecta a su tutela en el derecho común, la difamación es la expresión que comprende las distintas especies de ilícito civil contra la reputación de las personas, y que al igual que la denigración en materia de derecho de la competencia, comprende ataques realizados a través de manifestaciones lesivas contra la fama y buen nombre (honor) de las mismas ${ }^{17}$. En la difamación, no existe

fundamental, lo que no significa.... que el derecho al honor haya de prevalecer respecto al ejercicio que se haya hecho de aquellas libertades, ni tampoco siempre hayan de ser éstas consideradas como prevalentes, sino que se impone una necesaria y casuística ponderación entre uno y otro".

16 Vid. MASSAGUER FUENTES, José, Comentario..., op. cit., pág. 292, 1999.

17 Vid. MASSAGUER FUENTES, José, "Comentario a la sent.....», op. cit., pág. 775. “ ....denigración y difamación...Ambos comprenden la expresión y la difusión de manifestaciones lesivas de la fama de las personas, correspondiéndose plenamente en lo que atiende al descrédito mediante falsedades y parcialmente en lo que concierne al descrédito mediante la intromisión en la esfera intima y personal que sólo es relevante como denigración si la manifestación, aunque veraz, no es pertinente". 
una finalidad concurrencial, mientras que en la denigración, afecte la agresión a la esfera privada o a la profesional, se requiere la finalidad concurrencial (art. 2 LCD). Por tanto, la represión a través de la difamación se aplicará en aquellos casos en los que el ataque a la reputación de las personas no influya en la lucha competitiva ${ }^{18}$.

Este acto de difamación mercantil pero no competitivo, sería aquel acto denigratorio del empresario o de su actividad, procedente de un consumidor o de otro empresario al margen del ejercicio de su actividad mercantil, y que por tanto no tiene una finalidad competitiva en el mercado ${ }^{19}$, y que lesiona el prestigio mercantil a través de una crítica verbal injustificada o de una actuación inoportuna con una clara voluntad crítica.

Finalmente, la acción de difamación se utilizará para obtener el resarcimiento de los daños morales ocasionados por una actuación denigratoria, puesto que a través de la acción por denigración no se podría obtener esta tutela.

\section{2. Ámbito particular: desprestigio en el mercado}

En el ámbito particular la reputación de las personas se protege a través de la represión del ilícito desleal denigratorio cuando los actos lesivos se realicen en el mercado y posean finalidad concurrencial .

La denigración como supuesto constitutivo de competencia ilícita, es un acto de competencia desleal que se ha tipificado tradicionalmente en nuestro derecho ${ }^{20}$. La ley de Propiedad Industrial de 1902 en su artículo 132, ya recogía este supuesto estableciendo lo siguiente:

Se consideran como hechos constitutivos de competencia ilícita:

a) Propagar a sabiendas falsas aserciones contra un rival con objeto de quitarle su clientela.

18 Vid. MADRENAS i BOADAS, C., Sobre la interpretación...., op. cit., pág. 158 y ss. En concreto la autora señala que el criterio de distinción para saber si es aplicable la represión a través de la difamación o de la denigración es el de la relevancia del hecho para valorar la actividad económica, por lo que cuando se traten de hechos y actividades referentes a la persona que carecen de relevancia económica, no son susceptibles de ser enjuiciados a través del ilícito denigratorio. 
b)

ublicar anuncios, reclamos o artículos de periódicos que tiendan a depreciar la calidad de los productos de un contrincante.

Esta prohibición de la denigración a través del art. 132 de la ley de Propiedad Industrial, tuvo escasa transcendencia debido a su carácter penal ${ }^{21}$.

El viejo Estatuto de la Publicidad, de 11 de Junio de 1964, también recogió la denigración como supuesto de publicidad desleal, emitiendo el Jurado de la Publicidad algunas resoluciones sobre publicidad denigratoria. El Estatuto en su artículo 10, indicaba lo siguiente:

Es publicidad desleal...la que tienda a producir el descrédito de los competidores o de los productos de los mismos.

Posteriormente, la Ley de marcas de 1988, también incluyó como acto de competencia desleal en su artículo 88 b) "la difusión de aseveraciones falsas en el ejercicio del comercio que fueran capaces de desacreditar el establecimiento, los productos o las actividades de un competidor". Este precepto fue derogado expresamente por la Ley 3/91 de Competencia Desleal.

En la actualidad la tutela del acto denigratorio se realiza de un doble modo: a través de la Ley General de Publicidad, donde se recoge la publicidad denigratoria y a través de la Ley de Competencia Desleal, donde se regula la denigración como acto de competencia desleal. En ambos casos, la denigración, aunque afecte a la esfera estrictamente personal de un tercero, si se realiza con finalidad concurrencial entra en el ámbito del control de deslealtad.

\subsubsection{Tratamiento en la ley general de publicidad.}

La denigración supone potenciar las propias prestaciones a través de una agresión injustificada hacia la persona o las prestaciones ajenas. Con esta agresión difamatoria, se pretende desprestigiar al perjudicado con el propósito de mermar su crédito ante sus posibles clientes.

A la hora de hablar de publicidad denigratoria, hemos de tener en cuenta en primer lugar, el concepto de publicidad que ya hemos estudiado, para poder identificar la publicidad denigratoria y así deslindarla del acto desleal denigratorio en general. Por tanto la publicidad denigratoria tal como recoge la Ley General de Publicidad en sus artículos 2 y 6 a), sería:

toda forma de comunicación realizada por una persona física o jurídica, pública o privada, en el ejercicio de una actividad comercial, industrial, artesanal o profesional, con el fin de promover de forma directa o indirecta la contratación de bienes muebles o inmuebles, servicios derechos y

21 Vid. BERCOVITZ, Alberto, «Protección efectiva contra la competencia desleal con arreglo al artículo 10 del Convenio de Paris de 1883», pág. 16, 1994. 
obligaciones que por su contenido, forma de presentación o difusión provoca el descrédito, denigración o menosprecio directo o indirecto de una persona, empresa o de sus productos, servicios o actividades o circunstancias o de sus marcas, nombres comerciales u otros signos distintivos.

La denigración supone un concepto amplio, en el que el ilícito denigratorio se encuentra en el mensaje publicitario básico y la forma en que es presentado y como es difundido dicho mensaje. Tal como recoge el precepto, para que se produzca denigración el mensaje publicitario presuntamente denigratorio debe recoger dos presupuestos: que se efectúe una referencia explícita o implícita a un competidor y en segundo lugar, que se menoscabe su crédito en el mercado.

La finalidad del ilícito publicitario denigratorio es desacreditar, denigrar o menospreciar al competidor, sus productos o servicios, es decir, la L.G.P. exige textualmente que la publicidad provoque efectivamente la denigración en el oponente que parte de la doctrina entiende que no tiene por qué ser un competidor $^{22}$, a diferencia de lo establecido por el viejo $\mathrm{EP}^{23}$, que sí exigía la relación concurrencial.

Esta denigración o menosprecio es objetiva, y para la LGP, es indiferente el hecho de que el anunciante esté diciendo la verdad. Por el simple hecho de que se produzca el menoscabo a la credibilidad ajena (personal, de su producto, empresa o actividad) nos encontramos ante un supuesto de publicidad ilícita denigratoria 0 deshonrante ${ }^{24}$, propia de las claves de política legislativa del momento en que fue redactada la Ley.

Por lo que respecta a la referencia del lesionado por el acto publicitario denigratorio, también se recoge en el art. 6a) la posibilidad de denigrar de manera directa

22 DE LA CUESTA RUTE, José Ma, "Observaciones sobre la Ley General de Publicidad», op. cit., pág. 940 (74). La Ley para nada se refiere a que la víctima haya de ser necesariamente un rival o competidor del anunciante. El silencio legal es elocuente y no puede ser tomado más que en el sentido de que el descrédito publicitario puede producirse al margen de la existencia o no-existencia de una efectiva situación concurrencial entre el anunciante y la víctima. Con ello, sin duda, se cubren los casos de deslealtad provinente de un tercero (no concurrente) con fines de competencia, de los que la doctrina jurídica se ha ocupado ya hace tiempo.

23 El EP indicaba que serían actos desleales "Ios actos publicitarios que tiendan a producir el descrédito de los competidores o de los productos de los mismos".

24 Vid. CORREDOIRA y ALFONSO, Loreto, Comentarios a la Ley de publicidad, op. cit., pág 48. 
(haciéndolo expresamente) o indirecta ${ }^{25}$, a través de modos o medios encubiertos. Aunque no se diga el nombre del producto o del servicio, si la alusión reúne suficientes requisitos para que se pueda identificar al $\operatorname{competidor}^{26}$, o si el resultado es que se produce el descrédito o menosprecio de una persona, empresa o de sus productos, servicios o actividades, nos encontramos frente a un supuesto de denigración publicitaria.

El aludido en la denigración publicitaria, puede ser un competidor de manera individual, o un conjunto de competidores dentro de un mismo sector profesional o competitivo. ${ }^{27}$ Pero la denigración publicitaria se ha de entender dentro del anuncio en el que se encuentre, es decir, el anuncio se ha de analizar en su conjunto, atendiendo a la impresión global que genere en sus destinatarios, que si bien no se trata de público especializado y es general, se tratará de un consumidor medio, que en palabras del Tribunal de Justicia de la comunidad Europea, es un consumidor atento y razonablemente informado ${ }^{28}$. Este destinatario, será capaz de diferenciar el tono del mensaje, si se trata de información ofensiva que desacredita y menosprecia, o si nos encontramos ante un supuesto de exageración, o de tono

25 Vid. BURST, Jean-Jacques, Concurrence Déloyale et parasitisme, Dalloz, París, pág. 61...Pour que le dénigrement soit constitué, il est nécessaire que la victime soit identifiée ou, tout au moins, facilement identifiable.

26 En el caso "Megápoly", Resolución del Jurado AAP de 3 de noviembre de 2000, la reclamante aduce un supuesto de publicidad denigratoria implícita apoyándose en tres circunstancias: La característica principal de Monopoly es que consiste en la compra de calles (en el anuncio se compara el producto del anunciante con otro a través de la alusión no compre calles). Entre los juegos de mesa existentes en el mercado Monopoly es el que ha adquirido mayor notoriedad. Junto a Megápoly, son los únicos que se anuncian en televisión.

27 Vid Resolución del jurado AAP (sección cuarta) de 11 de mayo de 2000, caso Anna Kournikova. La reclamante era la Asociación en Defensa de los Derechos del Feriante en Cataluña, que sentía desprestigiados los derechos de ese colectivo por el anuncio emitido.

28 Sentencia del Tribunal de Justicia de 16 de julio de 1998, caso "Gut Springheide GmbH y Rudolf Tusky contra Oberkreisdirektor des Kreises Streinfurt" Vid. TATO PLAZA, A., "En torno a la reciente...», op. cit., pág. 41 . El autor hace referencia a la importante Sentencia del tribunal de Justicia de las Comunidades Europeas de 16 de julio de 1998, en la que el alto tribunal se atreve a trazar un prototipo del consumidor medio del que señala que por regla general está "normalmente informado" y es "razonablemente atento y perspicaz". 
humorístico y desenfadado ${ }^{29}$. En este caso no nos encontraremos ante un supuesto denigratorio.

El precepto recoge de manera expresa una subhipótesis de denigración publicitaria $^{30}$, como es la publicidad de tono personal, que estudiaremos en particular más adelante.

Finalmente, hemos de señalar, que como analizamos en el Capítulo I de este trabajo, en la actualidad la LGP, ha sido modificada, habiéndose aprobado con fecha 28 de octubre de 2002 , la Ley 39/2002 de transposición al ordenamiento jurídico español de diversas directivas comunitarias en materia de protección de los intereses de los consumidores y usuarios, entre las que se encuentra la Directiva 97/55/CE sobre publicidad engañosa y comparativa.

Esta transposición, en un principio, modifica la LGP adecuándola a la Directiva, y entre otros preceptos, afecta especialmente a la publicidad desleal. En concreto, por lo que respecta a la denigración, amplía la letra del artículo ${ }^{31}$ añadiendo una serie de supuestos donde recaería la denigración que sería en las circunstancias de una persona o empresa, 0 de sus marcas, nombres comerciales $u$ otros signos distintivos.

Desde nuestro punto de vista, esta ampliación no produce ningún cambio, ya que entendemos, que los mismos supuestos ahora recogidos, ya se incluían en la anterior redacción del precepto, ya que al señalar que sería publicidad denigratoria aquella que produjese descrédito o menosprecio, directo o indirecto, a través de su contenido, forma de presentación o difusión, en una persona, empresa, o de sus productos, servicios o actividades, ya se entendía incluidos los signos distintivos de los mismos y cualquier otra circunstancia susceptible de tener relevancia económica para el sujeto pasivo del acto denigratorio. Pensamos a este respecto, que el legislador debiera haber aprovechado la oportunidad para adecuar este concepto de denigración, al que recoge el art. 9 de la LCD, y así evitar inadecuados solapamientos e interpretaciones erróneas que se producen con relación a la

29 Resolución 11 de Mayo de 2000, caso “Anna Kournikova”. El Jurado de la AAP, no encuentra que exista denigración, al emplearse en el spot un tono ligero, humorístico y desenfadado.

30 Vid. LEMA DEVESA, Carlos, "Supuestos de Competencia desleal por denigración y comparación» en La regulación contra la Competencia Desleal en la Ley de 10 de enero de 1991, Edita B.O.E. Cámara de comercio e industria de Madrid, 1992, pág. 67.

31 El artículo ha quedado redactado de la siguiente manera: Es publicidad desleal: a) La que por su contenido, forma de presentación o difusión provoca el descrédito, denigración o menosprecio directo o indirecto de una persona o empresa, de sus productos, servicios, actividades o circunstancias, o de sus marcas, nombres comerciales $u$ otros signos distintivos. 
aplicación o no de la cláusula de la exceptio veritatis, cuya aplicación quedará al arbitrio de la interpretación del juez, lo que producirá, en algunos casos, situaciones de incoherencia como estudiaremos seguidamente ${ }^{32}$.

\subsubsection{Tratamiento en la ley de competencia desleal.}

El art. 9 de la L.C.D., incluye la denigración como un acto especial de competencia desleal $^{33}$ recogiéndose como elementos del ilícito de deslealtad concurrencial el menoscabo del crédito en el mercado del competidor aludido y la inexactitud, falsedad e impertinencia de las alegaciones versadas. ${ }^{34}$

El menoscabo del crédito en el mercado, supone la existencia de manifestaciones desacreditativas por parte del competidor hacia su contrincante sobre cualquier elemento de su condición de empresario, que producen en los terceros una depreciación en la opinión que les merecía. El carácter denigratorio debe reconocerse en el conjunto de las manifestaciones efectuadas, y no como consecuencia de expresiones aisladas o puntuales. Asimismo, la deslealtad se entenderá según las pautas de lo que es razonablemente creíble por el círculo de destinatarios del acto así como según los usos sociales y económicos del momento ${ }^{35}$.

Pero la novedad que introduce el presupuesto de ilicitud denigratoria de la LCD con relación a la LGP es el que para que se produzca el acto denigratorio, las afirmaciones que se realicen o difundan no deben ser exactas, verdaderas y pertinentes, o lo que es igual, deben ser falsas, aplicándose el principio de la "exceptio veritatis" en base a la tutela constitucional del derecho a la información y a las exigencias mismas de la competencia económica, ya que se perjudicaría

32 Vid. GIMENO OLCINA, Luis,. "Algunos problemas de la ley de Competencia Desleal», La Ley, no 3262, 1993, op. cit., pág. 5. El autor señala que las diferencias entre la LCD y la LGP no favorecen la creación de una doctrina consolidada y crean inseguridad jurídica.

33 El art. 9 LCD señala lo siguiente: "que se considera desleal la realización o difusión de manifestaciones sobre la actividad, las prestaciones, el establecimiento o las relaciones mercantiles de un tercero que sean aptas para menoscabar su crédito en el mercado, a no ser que sean exactas, verdaderas y pertinentes. En particular, no se estiman pertinentes las manifestaciones que tengan por objeto la nacionalidad, las creencias o ideología, la vida privada o cualesquiera otras circunstancias estrictamente personales del afectado".

34 MASSAGUER FUENTES, José, Comentario...op. cit., pág 622. “Una confrontación y ponderación entre el interés del agente económico profesional a no ser perturbado en el ejercicio de su actividad y el interés de la generalidad, y particularmente de los consumidores, a la existencia de una información de calidad sobre los extremos relevantes para la adopción de decisiones de mercado, se salda en una limitación de la deslealtad de la denigración a los supuestos en que el contenido material de la manifestación o expresión no sea exacto y verdadero o no sea pertinente.". 
considerablemente a los consumidores si se les privase de información veraz, cambiando la clave de política legislativa aplicada, que si en la LGP es la clave corporativa, en la LCD, es la clave institucional que velará porque todos los intereses en el mercado ${ }^{36}$, (interés de los competidores, interés de los consumidores e interés general), estén en un mismo nivel de protección. ${ }^{37}$

Por ello, al confrontar el artículo 9 de la LCD, con el artículo 6ª $)$ L.G.P., encontramos algunas diferencias bastante significativas:

La primera es como indicábamos, la aplicación de la exceptio veritatis: al señalar el art. 9 de la LCD, que para que exista denigración, las manifestaciones no tienen que ser exactas, verdaderas y pertinentes.

El diferente tratamiento entre el acto denigratorio general y el acto denigratorio publicitario, en cuanto a la aplicación de la veracidad en las aseveraciones desacreditativas emitidas, viene de lejos. En la antigua LPI (art. 132 ), al recoger como hecho constitutivo de competencia ilícita la denigración, ya se exige que se propaguen a sabiendas falsas aserciones, entendiéndose que las verdaderas afirmaciones, que implícitamente pudiesen desacreditar, no constituirían "per se", un supuesto de denigración.

Pero en el antiguo Estatuto de la Publicidad, no se dispone como requisito, la exigencia de la veracidad en las aseveraciones, sino que únicamente con que se produjese el descrédito, aunque sea a través de afirmaciones verdaderas, ya se produce la ilicitud de la publicidad, en una clara intención de protección corporativista.

Por manifestaciones verdaderas, se desprende que lo serán, aquellas que se viertan sobre hechos ciertos y demostrables que provoquen en los destinatarios una representación fiel de la realidad de las $\operatorname{cosas}^{38}$. Como se puede apreciar, la

36 MENENDEZ. Aurelio, La Competencia Desleal, op. cit., pág 108. "La "protección individual" (Individualschutz), articulada a través de la atribución de derechos subjetivos, es sustituida por la "protección institucional" (Institutionenschutz), que se instrumenta mediante la formación de instituciones con fuerza de Derecho objetivo al servicio de los intereses de la variedad de sujetos implicados en ellas. El Derecho de la competencia desleal se vincula así directamente a la conservación del orden económico de mercado..."

37 EMBID IRUJO, José Miguel, "La competencia desleal...», op. cit., pág. 146 “..el objeto de protección se traslada al orden económico del mercado, en el cual se integran los intereses individuales de los empresarios, los de los consumidores y el interés público del Estado".

38 Resolución de la sección Tercera del Jurado de la Publicidad de la AAP de 26 de septiembre de 2000; Caso "Zumos de Naranja, Don Simón "la reclamada, García Carrión indica que su publicidad no es denigratoria dado que afirmar que un zumo como "minute maid" se obtiene a partir del concentrado es un dato objetivo...Una minusvaloración del producto comparado es inevitable en este tipo de publicidad. Y el Jurado así lo reconoce al sostener que la comparación se ha efectuado de una manera totalmente objetiva y 
veracidad que se exige para que una alegación no se considere deslealmente denigratoria, debe tener un riguroso nivel de objetividad muy por encima del que se tiene para evitar el engaño ${ }^{39}$, coincidiendo la manifestación con la realidad objetiva en lo sustancial, no admitiéndose generalizaciones, y además tiene que ser demostrable.

La veracidad tiene que ser objetiva, y no fruto de una creencia subjetiva del anunciante $^{40}$. Por ello, las alegaciones inveraces, aún realizadas con buena fe por parte del anunciante, serán ilícitas por denigratorias.

Que las manifestaciones sean exactas supone que no quepan medias interpretaciones, sino que tienen que ser "puntuales, fieles y cabales" ${ }^{41}$. Esto nos llevará a que la publicación de una sentencia condenatoria de un competidor dentro de un contesto adecuado, no abusivo y efectuada de manera íntegra sin manifestaciones ni referencias a la misma, sería considerada lícita. ${ }^{42}$ También

aséptica, limitándose a transmitir al consumidor la diferencia existente en la naturaleza y en el proceso de elaboración de dos productos, sin emitir juicio de valor alguno en relación con cualquiera de ellos".

39 MASSAgUER FUENTES, José, Comentario...,op. cit., pág.624. TAPIA HERMIDA, A.J., «Publicidad comparativa. denigratoria y exceptio veritatis (a propósito de la sentencia de la Audiencia Provincial de Barcelona de 3 de Septiembre de 1996.)» ., RGD, 1997, pág. 14361, el autor señala que ..."los legítimos intereses del sujeto denigrado exigen que dicha veracidad se objetive al máximo..."

40 TAPIA HERMIDA, A.J., "Publicidad comparativa...», op. cit, pág. 14361, indica el autor que cuando un anunciante, tiene la creencia subjetiva de certeza sobre las alegaciones versadas, y ha realizado las comprobaciones oportunas sobre las mismas, se tendrá en cuenta a efectos del resarcimiento de los daños y perjuicios causados, en base a la diligencia observada.

41 Vid. OTAMENDI RODRIGUEZ-BETHENCOURT, Juan José, Competencia Desleal. Análisis de la Ley 3/1991, op. cit., pág. 152, el autor señala que: " la veracidad ha de tomarse en sentido estricto, no cabiendo pues que las manifestaciones fueran parcial o básicamente ciertas, sino que se corresponderán con la realidad de las cosas". TAPIA HERMIDA, Alberto Javier, " "Publicidad comparativa... ", op. cit., pág. 14355 y 14361 " la denigración veraz ha de corresponderse con la realidad objetiva y ser íntegramente demostrable", por este motivo el autor recoge las pistas que nos señala el Diccionario de la Lengua Española para indicar que el término "exactas" significa que las alegaciones deben ser "puntuales", como sinónimo de no extemporáneas .

42 BURST, Jean-Jacques, Concurrence déloyale et parasitisme, op. cit., pág 62 "...la jurisprudence refuse de condamner pour concurrence déloyale lorsque les faits incriminés sont exacts. Il en est ainsi de la publication d'une décision de justice condamnant un concurrent si elle n'est pas réalisée de façon abusive, notamment lorsqu'elle a lieu de façon incomplète ou accompagnée de commentaires." 
ignifica, que los datos han de ser precisos y actuales en el tiempo ${ }^{43}$, no empleándose datos antiguos que podrían engañar al consumidor.

$Y$ finalmente, el concepto pertinentes. Se entenderá por manifestaciones pertinentes aquellas que tengan una relación directa ${ }^{44} y$ adecuada ${ }^{45}$ con el objeto de la información ${ }^{46}$ y además resulten justificadas dentro del mensaje publicitario que se emita, puesto que dan más detalles del producto o servicio al público, suponen defenderse de ataques o amenazas del competidor o entran en la política de promoción de los propios productos o servicios.

Este último aspecto, el que las manifestaciones sean pertinentes, fue objeto de diversas enmiendas debido a la inconcreción del término y a su relación con el apartado dos del precepto. ${ }^{47}$ La enumeración ejemplificativa de supuestos no pertinentes recogidos en el apartado 2, presupone que manifestaciones verdaderas y exactas, que no tienen ninguna relación con el objeto de la información, producen un daño superfluo e inútil y por tanto ilícito. Es decir, no existe una proporción entre la necesidad de recurrir a una alegación denigratoria y el daño que ésta pueda producir.

43 ZURIMENDI, Aitor, «Publicidad comparativa y denigrante. En torno a la STS de 24 de febrero de 1997», R.G.D., no 654, 1999, pág. 2510.

$44 \quad$ Entendiendo por relación directa, la que se efectúe entre sujetos que participan en el mercado y dentro de un contexto publicitario (art. 2 LGP) y que las manifestaciones no sean irrelevantes o innecesarias dentro del mensaje publicitario que se emita.

45 TAPIA HERMIDA, A. J., "Publicidad comparativa...», op. cit., pág. 14362. El autor, haciendo una interpretación gramatical del término "pertinentes" indica que "es algo que viene a propósito" o como señala el Diccionario de MARIA MOLINER "es adecuado y oportuno en la ocasión o caso que se trata", por lo que señala que la pertinencia se debe aplicar a las manifestaciones denigratorias que resulten adecuadas con carácter general (se refiere a la participación en el mercado art. 1 LCD), con carácter particular (con relación al contexto concreto de las circunstancias que se producen) y resulten justificadas (como manifestación de un principio de economía de medios y de reducción de las lesiones al crédito ajeno).

46 En el recurso de alzada del Pleno del Jurado AAP de 2 de diciembre de 1999 "Caso Moulinex-BMW", el Jurado indica.... "que aunque se apoye en datos exactos y verdaderos, la denigración de un competidor en la publicidad también será incorrecta cuando aquélla sea impertinente ...es impertinente, porque realiza una denigración innecesaria al género de los microondas.".

47 La enmienda 42 del Congreso, y luego la no 49 y 80 del Senado pretendían la supresión del apartado 2 del artículo 9 indicando " en primer lugar, se trata de un precepto interpretativo, por lo que no debe figurar en el texto legal. En segundo lugar, produce el efecto contrario al que pretende, por ser sugerente e incitar a insinuaciones dañosas para la honra, fama e imagen del posible afectado, y, en tercer lugar, por ser en su redacción incompleto". 
Por lo demás, los presupuestos de no pertinencia que detalla el propio texto del artículo, en su apartado 2, son aquellos extremos que se consideran de tono personal o estrictamente personal, y que son un subtipo de publicidad denigratoria, tales como la nacionalidad, las creencias o ideología, la vida privada y cualesquiera otras circunstancias estrictamente personales del afectado, que posteriormente estudiaremos en otro apartado. Este presupuesto, no agota otros posibles supuestos de impertinencia.

Una segunda diferencia del artículo 9 de la LCD con la LGP se refiere a la finalidad del ilícito denigratorio, ya que la LCD únicamente exige la susceptibilidad de menoscabar el crédito de una empresa o productos ajenos ${ }^{48}$ para considerar que existe denigración, mientras que la LGP exige que se desacredite, denigre o menosprecie directa o indirectamente, pero que se produzca el hecho de la denigración, es decir, que la denigración sea efectiva ${ }^{49}$, por lo que se tendrá que alegar y probar el daño sufrido.

A diferencia de la LGP, el acto denigratorio recogido por la LCD será desleal cuando se menoscabe el crédito del competidor en el mercado de manera objetiva.

Por menoscabo del crédito del competidor se entiende cualquier lesión de la reputación o desprestigio del competidor, que pretende suprimirle o cuanto menos disminuir su posición en el mercado, a la vista de la reacción de los destinatarios consumidores. Por lo tanto lo que importa es si ha afectado en la opinión de los terceros, es decir, si éstos han recibido el mensaje de poca credibilidad respecto de las actividades, las prestaciones o el establecimiento del competidor o respecto sus relaciones mercantiles con un tercero ${ }^{50}$.

En tercer lugar, la LCD restringe más el objeto de la denigración ${ }^{51}$, puesto que en la LGP, la denigración recae sobre el actor, su empresa, productos, servicios o actividades y en la LCD además también incluye la posibilidad de que recaiga sobre un tercero con el que no mantiene una relación concurrencial directa. De esta

48 PEINADO GRACIA, Juan Ignacio. "Comparación y denigración publicitaria de la imagen de empresas indirectamente aludidas. (Reflexiones con ocasión de la Sentencia del Tribunal Supremo de 24 de febrero de 1997)», RDM, no 230, 1998, pág. 1623. "La LGP exige la denigración efectiva, recogiendo tan sólo la potencialidad en la $L C D "$.

49 Vid. GIMENO OLCINA, Luis,. «Algunos problemas de la ley de Competencia Desleal», La Ley, no 3262, 1993, op. cit., pág. 5.

51 BARONA VILAR, Silvia, Competencia Desleal, op. cit., pág. 57. LEMA DEVESA, Carlos, "Supuestos de Competencia Desleal....», op. cit, pág. 68. DE LA CUESTA RUTE, José Mạ " «Observaciones...», op. cit., pág. 940, el autor ya interpretaba el art. 6 a) de la LGP, en este sentido, aunque no se mantuviese con el tercero una relación concurrencial. 
manera se resuelven algunas dudas sobre el silencio de la LGP, sobre la existencia o no existencia de una efectiva situación concurrencial entre el anunciante y el presumible lesionado por el acto denigratorio.

De aquí se desprende que los medios que emplee el anunciante para realizar la publicidad ilícita, serán muy amplios, incluyéndose todos aquellos susceptibles de menoscabar su credibilidad en el mercado a través de actos propios como realizados por terceros ${ }^{52}$. Como indica LEMA DEVESA ${ }^{53}$, "si el anunciante difunde, en sus anuncios, alegaciones que realizaron terceros, pero que son susceptibles de desacreditar un producto, servicio o empresas competidoras, nos encontraríamos ante un supuesto de denigración publicitaria". Por lo que se da una interpretación extensa sobre los medios a emplear para realizar el acto ilícito. ${ }^{54}$

\subsubsection{Solución al concurso de la LGP y la LCD con relación al ilícito denigratorio.}

Como hemos indicado con anterioridad, la publicidad desleal es una forma de manifestación de la competencia desleal, por lo que considerando la disciplina concurrencial de una manera global y unitaria, no podemos desgajar de ella toda la materia que afecte a la publicidad desleal, sino que tendremos que interpretarlo de manera conjunta y armoniosa.

Como ya estudiamos en el capitulo primero ${ }^{55}$, de las soluciones aportadas por la doctrina para resolver el concurso normativo entre la LGP y la LCD, parece que el mecanismo de la derogación tácita por incompatibilidad junto con la interpretación integradora, será la más adecuada ${ }^{56}$. Sin embargo la derogación tácita debe ser aplicada de forma restrictiva, por lo que se intentará, en la medida de lo posible, conciliar ambas normas. ${ }^{57}$

52 BARONA VILAR, Silvia, Competencia Desleal, op. cit., pág 57 y 58 "Los medios serán todos aquellos que tiendan a restar credibilidad al contrario, que pueden ir desde el montaje de una campaña publicitaria denigratoria, pasando por afirmaciones vertidas públicamente en medios de comunicación, hasta por medio de catálogos o informaciones que se publiquen entre los sujetos receptores

53 LEMA DEVESA, Carlos, «Supuestos de Competencia Desleal...», op. cit.", pág. 68.

54 Como indica TATO PLAZA, Anxo: El descrédito del competidor afectará además de al contenido, a su forma de presentación y difusión. Vid., "La publicidad ilícita...», op. cit., pág 10.

55 Vid. Capítulo I, I, 2.2, pág.

56 Para parte de la doctrina (EMBID IRUJO, J.M, «La Competencia Desleal....».op. cit.”, pág. 147. PEINADO GRACIA, J.I. «Comparación y Denigración...», op. cit., pág. 1621. ), esta solución es una matización del criterio cronológico.

57 DíAZ RUIZ, Emilio, "Competencia Desleal a través de la Publicidad Comparativa», R.D.M., no 215, 1995, op. cit., pág. 97. "Al hablar de los criterios para determinar si hay derogación, que recoge el TS en la sentencia 28-X-1976 al respecto indica:..no está clara ni la intención legislativa ni los principios que han 
Por lo que respecta al acto desleal denigratorio, hemos visto que justamente en este supuesto, las soluciones que disponen ambas normas pueden entenderse como distintas e incluso contrapuestas. Dependerá, por lo tanto, del criterio del interpretador, la solución que se adopte.

Como la mayor parte de la doctrina indica, el hecho de la coexistencia de las dos normas produce indefinición a la hora de aplicar ambas leyes, produciéndose una situación confusa, que da como resultado interpretaciones contrapuestas. Este es el caso de la sentencia del Juzgado de primera Instancia de Alcobendas de 5 de noviembre de 1997, en la que se indica que en esta materia no cabe la exceptio veritatis, no teniendo en cuenta lo que dispone el art. 9 de la LCD, o la STS 24-II$1997^{58}$, que con relación al menoscabo del crédito se aplica un menoscabo efectivo, tal como el que recoge el art. $6^{2}$ ) de la LGP, olvidando que la LCD solo requiere la mera susceptibilidad de que se pueda producir el acto denigratorio.

En la actualidad, una gran parte de la doctrina que ha opinado al respecto ${ }^{59}$, parece estar de acuerdo en la "forzosa pacífica convivencia"60 de ambas normas, pudiéndose aplicar las mismas, de manera alternativa o conjunta, teniendo como premisa que allí donde pudiera haber conflicto, se interpretará con arreglo a lo dispuesto en la LCD, que era la Ley posterior, y que aunque no deroga lo dispuesto en materia de publicidad desleal, porque así se recoge expresamente en el mismo preámbulo ${ }^{61}$, sí que la completa, aplicándose lo en ella dispuesto como solución en aquellos aspectos donde se produzcan controversias, y respondiéndose de esta forma, a criterios de política legislativa actuales y no desfasados.

\footnotetext{
inspirado una y otra ley, ya que sólo la LCD enuncia cuales son estos principios, no está claro cuales son los destinatarios de ambas leyes pues, en general, la LCD tiene como destinatarios a un número de personas más amplio que la LGP, de carácter más profesional, y, sobre todo, como la doctrina tiene ya dicho desde hace mucho tiempo, es preciso que haya una total incompatibilidad entre los fines de los preceptos de tal manera que no puedan conciliarse en modo alguno"

$58 \quad$ RJ $1997 / 1195$

59 Vid. MASSAGUER FUENTES, José, Comentario... op. cit., pág. 66. TATO PLAZA, Anxo, La publicidad comparativa, op. cit., pág. . PORTELLANO DÍEZ, Pedro, La imitación en el...., op. cit,. Entre otros. 
Por lo que respecta al ilícito denigratorio, la interpretación del mismo con el concurso de ambas normas, presupone que apliquemos la exceptio veritatis ${ }^{62}$ como presupuesto del ilícito denigratorio, así como que no se requerirá la efectividad del daño producido por la ilicitud, sino que la simple susceptibilidad de que se produzca la lesión hará efectiva dicha ilicitud.

Finalmente hemos de señalar, que con la modificación de la Ley General de Publicidad por la Ley 39/2002, el legislador español ha perdido una oportunidad de adecuar las contradicciones entre la LGP y la $L C D^{63}$. Ya que si bien es cierto, que alabamos la oportunidad de modificar y ampliar la cláusula general de deslealtad en la publicidad, que aumenta la inclusión de los comportamientos contrarios a la exigencia de la buena fe, no nos parece correcto que no haya adecuado la denigración publicitaria a los términos que recoge la LCD, dejándolo al criterio interpretador del juzgador, que siempre será más endeble que lo tipificado por la norma.

2.2.3.1. La aplicación de "la exceptio veritatis" en los supuestos de publicidad denigratoria.

Como hemos señalado, tras la entrada en vigor de la $L C D^{64}$, a nuesto entender, la interpretación del art. 6 a) de la LGP se resolvería en favor de la aplicación de la exceptio veritatis ${ }^{65}$. Se presupone la licitud de la denigración veraz, es decir, la licitud de aquella publicidad que se fundamente en manifestaciones exactas, verdaderas y pertinentes. Esta licitud se sostiene en dos fundamentos:

62 Como excepción que es, la exceptio veritatis se aplicará siempre de forma restrictiva, y máxime cuando en muchas ocasiones se utilizará a través de la publicidad comparativa, por lo que se convertirá en una excepción de la "excepción".

63 Vid. DE LA CUESTA RUTE, J.Mạ., Curso de ...., op. cit., pág. 183.

64 La SAP de la Coruña de 18 de Abril de 1995 (AC, 1314), sobre actos de confusión y denigración realizados en 1990, la demandante comercializaba un vino con el nombre de "Blanco turbio", y alegó que la publicidad de la demandada indicaba que la turbidez es característica descalificadora de un vino, y alegó en defensa de esta actuación, que este enunciado es un pensamiento común de las gentes, público y notorio en Galicia, cuya desaparición de la turbidez del vino se ha logrado precisamente, con el control de calidad que aplican las diferentes denominaciones de origen. Por lo que la nota donde se recogía el enunciado controvertido, no fue considerada como un acto de competencia desleal por denigración por la AP de la Coruña.

65 Como hemos señalado, esta postura no es pacífica, y parte de la doctrina se muestra contraria a que a las manifestaciones publicitarias denigratorias se le aplique la exceptio veritatis. Vid. BROSETA PONT, M./MARTINEZ SANZ, F., Manual de..., op. cit., pág. 199. 
En primer lugar, en el derecho a la información que tiene el consumidor y que afectará a la racionalidad del comportamiento del consumidor en el mercado, y que tendrá más transcendencia cuando se realiza a través de un soporte publicitario ${ }^{66}$.

Y en segundo lugar, en el carácter posterior en el tiempo de la LCD complementado con un criterio de carácter sustancial: las conductas relevantes de publicidad denigratoria y de acto de denigración, son sustancialmente idénticas, por lo que como indica MASSAGUER ${ }^{67}$ "debe descartarse enteramente que el enjuiciamiento material de la actividad publicitaria sea distinto según se aplique una u otra norma, a pesar de las diferencias de tenor entre los preceptos de la LGP y de la LCD. Un eventual conflicto entre la $L G P$ y la $L C D$ ha de resolverse, en efecto, en favor de ésta última". La LCD al admitir la exceptio veritatis, expresa un principio informador de la disciplina de la competencia que se deduce de su propio concepto y función ${ }^{68}$, por lo que así se deberá interpretar el art. 6 a) de la LGP, apoyándonos también en que esta interpretación no se excluye por dicho precepto.

Es cierto, que desde la modificación de la LGP el 28 de octubre de 2002, hay autores que dudan de la condición de la Ley de Competencia Desleal como lex posterior $^{69}$, pero a nuestro entender, dicha modificación se ha debido a la transposición de la Directiva 97/55/CE sobre Publicidad comparativa por lo que prácticamente se ha limitado a la transcripción del nuevo tratamiento de la publicidad comparativa tal como se recogía en la Directiva, dejando de lado aspectos tan importantes como la estructura de los comportamientos desleales publicitarios (tras la reforma de la Ley, hemos indicado que se sigue excluyendo como publicidad desleal la publicidad engañosa y no por ello dejaremos de considerarla un comportamiento publicitario desleal) o la aplicación de la exceptio veritatis a la denigración publicitaria.

Pero, para que se pueda aplicar la exceptio veritatis a los supuestos de publicidad denigratoria, se tiene que interpretar de manera estricta, ya que no debemos olvidar que al tratarse de una excepción de un supuesto grave como es el menoscabo y el descrédito hacia el competidor, la excepción del mismo vendrá derivada por motivos de clave política, dirigidos a que el consumidor esté bien informado y así pueda

66 TAPIA HERMIDA, A.J, «Publicidad comparativa...» op cit., pág. 14357, el autor fundamenta la admisibilidad de la "exceptio veritatis" en base a tres argumentos: El criterio teleológico, el criterio cronológico y el criterio de especialidad. Y dentro del primero (criterio teleológico), indica que el fundamento de la exceptio veritatis, se encuentra en el derecho constitucional a la información. DE LA CUESTA RUTE, J.Ma..,Curso de...., op. cit., pág. 182. El autor señala que las informaciones verdaderas suponen una ampliación del flujo de señales que favorece el acierto de las decisiones. 
realizar su elección de forma correcta ${ }^{70}$. Este presupuesto, no debe enturbiar la interpretación del juego de la exceptio veritatis, y para ello se tendrán en cuenta los requisitos de carácter sustantivo que recoge la propia cláusula ${ }^{71}$ y que como vimos anteriormente $^{72}$, son: la exactitud, la veracidad y la pertinencia ${ }^{73}$ de las manifestaciones desacreditatorias. En caso contrario, si hay falsedad, inexactitud o impertinencia, estaremos frente a un supuesto de publicidad denigratoria.

Hay que tener en cuenta que, para entender estos requisitos (exactitud, veracidad y pertinencia) estaremos, no a la interpretación literal del anuncio sino al mensaje en su conjunto y a lo que percibe el público destinatario. Estas matizaciones señaladas son muy importantes, puesto que nos permitirán vislumbrar si la denigración es un efecto derivado del juego del mercado del anunciante, es decir si éste emite las alocuciones presuntamente difamatorias en el contexto de dar más detalles o información sobre sus productos a los consumidores, o las realiza defendiéndose de un ataque a sus productos o empresa, por parte del competidor etc., o bien realmente se trata de un supuesto que únicamente pretende desprestigiar al competidor. Por tanto, si el supuesto menoscabo es cierto, exacto y pertinente, no existe denigración, a no ser que el menosprecio sea improcedente o innecesario y vaya más allá de dar una información al público destinatario.

2.2.3.2. Susceptibilidad de menoscabar el crédito de un competidor, su empresa, producto o servicio.

El segundo supuesto se refiere a que la existencia del posible ilícito denigratorio dependerá simplemente de que el mensaje publicitario sea apto para menoscabar el crédito en el mercado del competidor, y no será necesario someterlo al resultado efectivo de la denigración, como la LGP requiere.

Al aplicar la "exceptio veritatis", el nivel de objetividad de las manifestaciones publicitarias presumiblemente denigratorias será muy amplio, por lo que no será necesario que se efectúe el acto desacreditatorio concreto, sino, que con la

70 Vid. DE LA CUESTA RUTE, J. Mạ., Curso de..., op. cit., pág. 182. El autor señala que si lo manifestado es verdadero, aunque con ello se rebaje la estima de las prestaciones de un agente económico, no puede producir lesión al bien jurídicamente protegible del crédito comercial, pues éste ha de estar objetivamente fundado, y, consiguientemente, remover la estimación meramente subjetiva de la fama comercial constituye una acción que debe ser incentivada en beneficio de la promoción del verdadero bien jurídico protegible, que es el buen funcionamiento del mercado como instrumento para la eficiente asignación de recursos.

71 TAPIA HERMIDA, Alberto, «Publicidad comparativa...»,op. cit. pág. 14360.

72 Vid. Supra. Cap. III, I, 2.2.2. 
susceptibilidad de que se pueda menoscabar el crédito es suficiente, por lo que la denigración no tendrá que materializarse de hecho. Esto supone que únicamente probando que el acto publicitario (presumiblemente denigratorio) es susceptible de producir desprecio hacia los competidores, será considerado ilícito, siendo irrelevante la intencionalidad del autor, o si se ha producido o no, el resultado denigratorio ${ }^{74}$.

\section{Referencias}

BARONA VILAR, Silvia, Competencia Desleal, Tirant lo Blanch, 2ª Edición, 1999. Valencia.

BERCOVITZ, Alberto, «Protección efectiva contra la competencia desleal con arreglo al artículo 10 del Convenio de Paris de 1883», Informes Copenhague 1994.

BIENDICHO GRACIA, Luis F, «La protección del prestigio comercial de la entidad mercantil frente a los actos difamatorios: Los límites del derecho de crítica del consumidor», La Ley, 1999.

BROSETA PONT, M./Martinez Sanz, F., Manual de Derecho Mercantil, 9 edición, Madrid, 1991.

BURST, Jean-Jacques, Concurrence Déloyale et parasitisme, Dalloz, París. 1993.

CORREDOIRA Y ALFONSO, Loreto, Comentarios a la Ley de publicidad, 34/1988 y disposiciones complementarias". Bosch, casa editorial SA, Barcelona. 1993.

CUCHI DENIA, Javier Manuel, «La libertad de información versus el derecho al honor ¿De la técnica de la ponderación a la prevalencia de la primera?», R.G.D., nº 618, 1996.

DE LA CUESTA RUTE, José $M^{a}$, «Observaciones sobre la Ley General de Publicidad», Revista Jurídica de Cataluña. N 4. 1989. Barcelona.

DE LA CUESTA RUTE, J. Mª., Curso de Derecho de la Publicidad. Pamplona. 2002.

DÍAZ RUIZ, Emilio, «Competencia Desleal a través de la Publicidad Comparativa», R.D.M., $\mathrm{n}^{\circ}$ 215, 1995,

Diccionario Enciclopédico Larousse. Tomo 8.

EMBID IRUJO, José Miguel, «La competencia deslealen derecho español.». Texto de la ponencia presentada al XIII Congreso de la Asociación Hispano-

74 Vid. Infra. Cap. III, II, 2.1.1.Resolución de la Sección segunda del Jurado de AAP de 4 de septiembre de 1996, (caso “VinoVegaverde). 
Alemana de Juristas celebrado en Valencia del 29 al 31 de Mayo de 1997.C.D.C., n 24. 1997.

FERNÁNDEZ-NOVOA, Carlos, "La Publicidad de tono estrictamente personal», Estudios de Derecho de la Publicidad en homenaje a Joaquín Garrigues. Madrid. 1971.

GIMENO OLCINA, Luis,. «Algunos problemas de la ley de Competencia Desleal», La Ley, n 3262, 1993.

LEMA DEVESA, Carlos, "Supuestos de Competencia desleal por denigración y comparación» en La regulación contra la Competencia Desleal en la Ley de 10 de enero de 1991, Edita B.O.E. Cámara de comercio e industria de Madrid, 1992.

MADRENAS I BOADAS, C., Sobre la interpretación de las prohibiciones de publicidad engañosa y desleal. La parcialidad de la publicidad y los costes de la competencia. Cuadernos Civitas, Madrid, 1990.

MASSAGUER FUENTES, José, Comentario a la LCD. Editorial Civitas. Madrid 1999.

MENENDEZ. Aurelio, La Competencia Desleal. Civitas. Madrid. 1988.

OTAMENDI RODRIGUEZ-BETHENCOURT, Juan José, Competencia Desleal. Análisis de la Ley 3/1991.Editorial Aranzadi, Pamplona. 1992.

PEINADO GRACIA, Juan Ignacio. «Comparación y denigración publicitaria de la imagen de empresas indirectamente aludidas. (Reflexiones con ocasión de la Sentencia del Tribunal Supremo de 24 de febrero de 1997)», RDM, n 230, 1998,

TAPIA HERMIDA, Alberto Javier, « Publicidad comparativa denigratoria y exceptio veritatis (A propósito de la sentencia de la Audiencia Provincial de Barcelona de 3 de Septiembre de 1996)», Revista general de Derecho, 632, 1997.

TATO PLAZA, Anxo «La publicidad ilícita en la jurisprudencia y en la doctrina del jurado de la Publicidad», RAAP № 27, enero 1999.

ZURIMENDI, Aitor, «Publicidad comparativa y denigrante. En torno a la STS de 24 de febrero de 1997», R.G.D., n 654, 1999 